\title{
Sleep Duration and Daytime Sleepiness in Indian Adolescents: Is There a Gender Difference?
}

\author{
Bindu John
}

Received: 17 December 2013 / Accepted: 7 April 2014 / Published online: 4 May 2014

(C) Dr. K C Chaudhuri Foundation 2014

To the Editor: Studies on adolescent sleep show that adolescents are not obtaining optimum hours of sleep recommended for their age group, which is $9.2 \mathrm{~h}$ across all pubertal ages [1,2]. Many adolescents are reported to have sleep problems, which can cause chronic deprived sleep and excessive daytime sleepiness, leading to negative effects on individual performance and health $[2,3]$. Almost 45 to $85 \%$ of sixth to 12 th grade students obtain less than recommended hours of sleep for their age group and $44 \%$ of students report to have difficulty staying awake in school times [4]. However, only few studies have been done on excessive daytime sleepiness among adolescents in Asia.

The daytime sleepiness and the association of gender with sleep duration and daytime sleepiness was assessed among sixth to 12th grade students between 11 and $17 \mathrm{y}$ and studying in various schools in Mangalore, India. The adolescents were randomly selected using stratified random sampling method. Stratification was based on gender. The data was collected in July and August 2013. Sleep duration was assessed in hours using questions like "how much sleep do you get on an average during a school day?". Daytime sleepiness was assessed using Cleveland Adolescent Sleepiness Questionnaire developed by Spilsbury et al. [5].

A total of 58 adolescents, 29 males and females each, participated in the study. When classified according to groups (adolescent classification by American Academy of Pediatrics) 31 of them were early adolescents (11-14 y) and 27 of them were middle adolescents (15-17 y).

The adolescents were not obtaining the recommended hours of sleep for their age group on week days, as shown by a catch up sleep during weekends $(7.68 \pm 0.99 \mathrm{~h} v s .8 .70 \pm$ $1.63 \mathrm{~h}$ ). Early adolescents obtained better sleep than middle adolescents'. The mean daytime sleepiness scores for

B. John $(\bowtie)$

College of Health Sciences, University of Bahrain, P.O.Box.32038,

Sakeer, Bahrain

e-mail: binduthycad@hotmail.com adolescents were $36.83 \pm 8.38$, higher in middle adolescents and among female adolescents. Sleep duration and daytime sleepiness by gender however showed no statistically significant differences between male and female adolescents. Negative correlation between sleep duration and daytime sleepiness $(r=-0.295$ and $p$ value 0.025$)$ shows that as sleep duration increases, daytime sleepiness decreases.

This study highlights the importance of adolescent sleep and provides an evidence for the direction of future research. It also provides an implication that adolescents' suffer significantly with daytime sleepiness and future results could provide more insight into this existing evidence.

Acknowledgments I would like to thank sincerely the schools, and the students participated in the study. I would also like to express my gratitude towards Mr. Hassan Al Basri, Senior Lecturer in Statistics, College of Health Sciences for the statistical discussions.

\section{Conflict of Interest None.}

Role of Funding Source None.

\section{References}

1. Wolfson AR, Carskadon MA. Sleep schedules and daytime functioning in adolescents. Child Dev. 1998;69:875-87.

2. Millman RP. Excessive sleepiness in adolescents and young adults: causes, consequences, and treatment strategies. Pediatrics. 2005;115: 1774-86. doi:10.1542/peds.2005-0772.

3. Li S, Arguelles L, Jiang F, Chen W, Jin X, Yan C, et al. Sleep, school performance, and a school-based intervention among school-aged children: a sleep series study in China. PLoS One. 2013;8:e67928. doi:10.1371/journal.pone.0067928.

4. Asarnow LD, McGlinchey E, Harvey AG. The effects of bedtime and sleep duration on academic and emotional outcomes in a nationally representative sample of adolescents. J Adolesc Health. 2013; http:// dx.doi.org/10.1016/jadohealth.2013.09.004.

5. Spilsbury JC, Drotar D, Rosen CL, Redline S. The Cleveland adolescent sleepiness questionnaire: a new measure to assess excessive daytime sleepiness in adolescents. J Clin Sleep Med. 2007;3:603-12. 